\section{ANC-led government 'will protect funds for basic research'}

Cape Town. In her first scheduled engagement as Deputy Minister of Arts, Culture, Science and Technology, Mrs Winnie Mandela last week emphasized that science and technology have an important role to play in meeting the priorities of the new government.

Mandela's speech was due to be delivered to a regular meeting of the Science and Technology Initiative (a grouping of representatives from the science councils, universities, state-owned corporations and the private sector) at Midrand, halfway between Pretoria and Johannesburg. But having turned up two hours late - and after the meeting had officially closed - she ended up addressing those of the committee members who were still present.

The speech reiterated that the coalition government, led by the African National Congress (ANC), is likely to follow a path "which will direct research and development activities towards economic growth, competitive advantage and meeting the needs of all our people". But Mandela assured the research community that the ANC still held a positive attitude towards basic research. "We do not accept the view that basic and applied research should be in conflict with each other," she said.

In her speech, Mandela also referred to the legacy of scientific illiteracy and the shortage of technical expertise in the country arising from apartheid, pointing out that 96 per cent of the country's engineers, and 89 per cent of its scientists, are white.

She praised the Science and Technology Initiative for commissioning a report on affirmative action programmes for science councils, which was tabled at the meeting.

No appointments have yet been made to any positions in the new ministry. But last Friday Mandela announced the members of an ad hoc committee set up to advise the minister, Ben Ngubane, and herself.

This includes Koos Pauw, deputy director-general at the Department of National Education; Roger Jardine, ANC science and technology policy coordinator; Michael Kahn, from the Centre for Education Policy Development; and Isaac Amuaah, from the Foundation for Research Development.

The committee will be responsible for targeting science and technology policy towards the goals of the ANC's reconstruction and development programme. There are few indications as to what exactly this will involve, except that Mrs Mandela's speech made reference to the importance of environmentally clean technology. It is also considering introducing incentives to persuade industry to spend more of its profits on research and development. Michael Cherry

\title{
NASA head urges new focus on search for habitable planet
}

Baltimore. Daniel Goldin, the administrator of the National Aeronautics and Space Administration (NASA), suggested last week that the agency should adopt as a new 'unifying mission' the search for a habitable planet close to a nearby star.

Addressing the spring meeting of the American Geophysical Union (AGU), Goldin said that such a goal would allow the agency to continue to pursue much of the science that it is currently supporting. But it would also give NASA a concrete objective that the American public would understand.

Before the collapse of the Soviet Union, said Goldin, the space agency had been given a simple task that the whole of America endorsed: beating the "evil empire". But with the ending of the Cold War, that task had become meaningless.

The public want to know about science, he said, but finds little of interest in NASA's current space programmes. The key is to find a unifying theme, and the search for a habitable planet could fit the bill. "We need goals to integrate the space sciences and give the public something to understand."

The search for such a planet, which might be within ten or so light years from Earth, would require missions such as those already planned to Pluto, Mars, and the asteroid belt, in order to understand how planetary systems are formed. It would also be necessary to understand star formation, as well as phenomena such as protoplanetary disks.

"This is the 75th anniversary of the AGU,"
Goldin said, stressing that his suggestion was intended primarily as a way of opening up a debate in the scientific community. "It would be fantastic if, at the 100th anniversary, someone could present an image of a planet which is habitable, and which is not the Earth."

The NASA administrator claimed that even ancient civilizations had recognized the need for a vision. Rome had eaten itself to death when it stopped building roads and monuments and, if it continued to focus on short-term problems such as fixing the budget deficit, the United States was in danger of doing the same.

Challenged after his talk on why, if he felt NASA ought to pursue such a vision, its earlier Search for Extraterrestrial Intelligence (SETI) programme has been cancelled, Goldin pointed out that this decision was taken by Congress, not the space agency.

$\mathrm{He}$ also warned that, even if Congress were to cancel the international space station, the "feeding frenzy" that is likely to follow would not necessarily mean that the money is reallocated to alternative space projects.

Goldin's call for smaller, cheaper missions with a unifying focus has widespread support both inside and outside the agency. But many are sceptical about whether, even if the search for a habitable planet is a goal that fires the public's imagination, Congress - given its attitude towards SETI — would find it acceptable.

\section{Switzerland eyes bill for Framework}

Basel. Swiss scientists' fears that government funds for basic research could be sacrificed in order to support Switzerland's participation in the European Union's fourth five-year Framework programme seem to be justified (see last week's Nature page 264).

Last week, the government put forward a bill, due to be discussed by parliament later this month, asking for an additional SFr261 million (US\$180 million) to make up an expected shortfall between 1995 and 1999. The shortfall has been created by a difference between Switzerland's original estimates of the costs of its participation in Framework and subsequent calculations based on the increased costs of the new programme.

But the government also suggests that SFr176 million of this should be transferred from other budgets. SFr133 million would be taken from the budget allocated to the three priority programmes of the Swiss National Funds, covering environment, biotech and informatics. The rest of the savings will be shared among the research budgets of government agencies dealing with the environment, agriculture and economics.

Two weeks ago, a letter from five Swiss Nobel prizewinners expressing concern that Swiss research may be asked to pay too high a price for participation in the EC framework programme was leaked to the press. According to newspaper reports, the scientists argued that national research is more valuable, and of higher quality, than that carried out within the Framework programmes.

But Richard Ernst from the ETH Zurich, Switzerland's federal university, has condemned the leak. He says that the letter had been misinterpreted.

Oliver Klaffke 